\title{
A comparative study that investigates the treatment of technical terms, acronyms and numbers in a Tsonga technical target text
}

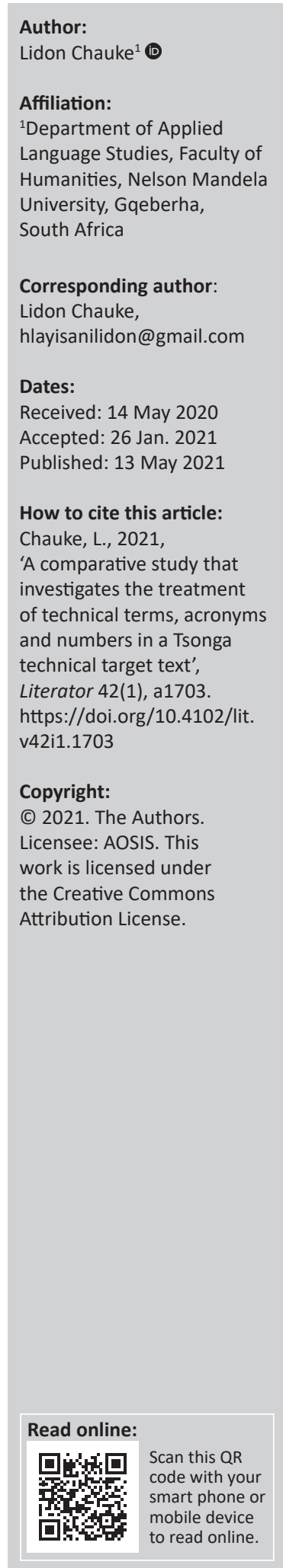

In each and every translated text, there is a certain intended meaning that is being communicated to the target reader or audience in their target language, which is equivalent to what is in the source text. Nonetheless, there is still a big debate on whether a translation should follow the communicative meaning or the semantic meaning when conveying the communicated message. This article provides an analysis and application of Toury's Descriptive Translation Studies (DTS) methodology on the treatment of technical terms, abbreviations or acronyms and numbers in a Tsonga target text. It also investigated the strategies applied by the translator to close the gap between the two languages in question (Tsonga and English), which vary significantly when we compare their instrumental value, hegemony and economic status.

Keywords: Tsonga; translation strategies; technical translation; neologism; semantic translation; communicative translation; descriptive translation studies; JICA.

\section{Introduction}

In providing a definition of the above-mentioned key concepts (respectively) in translation, Newmark (1981) stipulates that:

Communicative translation attempts to produce on its readers an effect as close as possible to that obtained on the readers of the original. Semantic translation attempts to render, as closely as the semantic and syntactic structures of the second language allow, the exact contextual meaning of the original. (p. 39)

With that being said, these two models of translation are present for selection by the translator when the need arises. What this means is, the translator can opt to use either communicative translation or semantic translation depending on the type of texts they are dealing with and the gaps between the language combinations in question. Thus, Toury provides a methodology for analysing and describing existing translations, which consists of the following three steps:

1. Situating the translated text within the target culture's literary poly system, looking at its significance and acceptability. This will provide the researcher with an intuition on whether the translation was rendered semantically or communicatively.

2. Comparing both the source text and the target text for shifts, identifying relationships between 'coupled pairs' of source text and target text segments. These are used to identify translation shifts: obligatory and non-obligatory.

3. Attempting generalisations, reconstructing the process of translation for this source texttarget text pair.

Following this three-phase descriptive translation studies (DTS) ${ }^{1}$ analysis, this study aims to investigate the ways in which technical terms, abbreviations or acronyms and numbers are treated in a translated Tsonga brochure - a brochure made available by the Japan International Cooperation Agency (JICA) with the title JICA volunteer activities 10th Anniversary in South Africa. The researcher, by following the three-step methodology, starts by situating the target text in the target culture system, finds how the above-mentioned linguistic constructions (technical terms, abbreviations or acronyms and numbers) are treated in the target text and subsequently generalise by looking at the norms that the translator followed during the process of translating the target text. Because this is a comparative study, comparing two unrelated languages from different cultures, it is useful to begin by discussing the aspect of culture as an influential factor in translation.

1.According to Toury (1980:116), this is a hypothetical construct [...] in the methodology of descriptive translation studies, serving as an intermediary invariant for any actual comparison of TT [target text]and ST [source text]'. 


\section{Culture as an influential factor in translation}

According to Hosseinimanesh and Dastjerdi's (2013) discourse, science, genres and writing techniques are formed in a cultural and historical context. Even at the level of terminology, serious problems exist in technical texts for translation (2013:156). Newmark (1988) advises that before a translator translates a text, he or she should look for possible cultural differences between the two languages involved (Newmark 1988:151). For this reason, every translator has to have a full grasp and mastery of the target language conventions, culture, genre conventions and register. Along the same lines, Bosco (1997) asserts that:

We have to remember that translation is not just a movement between two languages but also between two cultures. Cultural transposition is present in all translation as degrees of free textual adaptation departing from maximally literal translation, and involves replacing items whose roots are in the source language culture with elements that are indigenous to the target language. The translator exercises a degree of choice in his or her use of indigenous features, and, as a consequence, successful translation may depend on the translator's command of cultural assumptions in each language in which he or she works. (p. 11, in Soualmia 2010:18)

With every literary culture consisting of different types of literature, the two literary cultures in question, English and Tsonga appear to differ drastically. It is without any question that the English literary culture is more developed than the Tsonga one in all respects, for example, novels, serious literature, science literature, horror stories, children's literature, parables and so on. With that being said, the Tsonga literary culture most dominantly consists of translated literature more than any other (Maluleke 2017). This is because of the different levels of development, history and hegemony that the English language possesses. English is used as a major language in many parts of the world; in both the written form and verbally; however, Tsonga is only used by a minority group of people in South Africa (Statistics South Africa 2011). ${ }^{2}$ Essentially, when these two languages and literary systems are compared, one may find out that there are very little similarities and relations if any - Tsonga does not come anywhere close to ${ }^{3}$ English in its number of speakers, hegemony and instrumental value. That is, regardless of the fact that both languages have their own literary system, they do not share equal literary privileges. English rarely needs any translation ${ }^{4}$; however, both serious and science literature would have to be translated to Tsonga from English. ${ }^{5}$

Furthermore, the text that is discussed in this article is the one on an organisation called 'Japan International Cooperation Agency' (JICA). The text was distributed to

2.With other varieties being spoken in Mozambique, Zimbabwe and Swaziland.

3.It occupies a less-dominant literary position.

4.Although some parts of the English literature have been translated from other languages, that is, Latin, Greek, French and German, the language has enough scientific concepts and terminology.

5.In some cases, Portuguese, French, German and so on. some members of the South African public (particularly those who are Tsonga speakers), with the objective of persuading them to becoming members of the agency. This is a technical document with many technical terms. It was written by the language division of the agency and translated into Tsonga so as to reach the target readership in their own language. As the Tsonga literary culture is both young and peripheral, as alluded in the above paragraph, the text (document) will occupy a more important position and will form part of the most important literature in the literary culture system. Therefore, it is against this backdrop that the literary culture system of the target audience should always be considered when translating a text, particularly in cases where the two literary cultures involved vary drastically. As important parts of this article, the background and rationale are discussed in detail in the following section.

\section{Background and rationale}

This research project seeks to apply the descriptive model of translation, such as Toury's (1995) three-phase methodology, for the analysis of a translation. This will provide the researcher with an insight on how translators deal with certain expressions, sentence constructions and word formations in Tsonga translations; particularly in technical documents (consisting of technical terms). The rationale of this study is to investigate the treatment of technical terms, abbreviations, acronyms and numbers during a process of translating a document from the English source text into the Tsonga target text. By finding out how the above-mentioned linguistic constructs are treated in a Tsonga target text, this will provide reference to future translations and will render new translators with strategies that need to be taken and followed when translating technical documents.

Again, embarking on this research study aids in demonstrating how linguistic gaps are closed when translating a document from English into Tsonga. It is with no doubt that there are differences in the two languages in question; the differences between the source language (English) and target language (Tsonga) contribute to the different translation methods to be employed when translating. Considering the different standards and statuses of these languages, there has to be an informed method of translating, which is basically going to consider different aspects such as the culture and the linguistic cultural system of the target readership. Toury is also of the view that 'translations first and foremost occupy a position in the social and literary system of the target culture, and this position determines the translation strategies that are employed' (Toury 1995:13). Using this statement by Toury, in this research study, the researcher aims not only to determine and expose the treatment of technical terms, abbreviations, acronyms and numbers in the Tsonga translated text but also to investigate the translation strategies that are used in the translated product.

The researcher sets out to determine whether the consideration of culture and acceptability of the text played a role in the 
outcome of translation. The following research questions will be investigated: did the Tsonga culture have an influence on the treatment of technical terms during the translation process? Why the abbreviations from the English source text were retained in the Tsonga version of the text? These are the questions that are answered in this article.

Furthermore, Toury ([1978] 2004) states that 'in practice, no translation is ever fully "adequate" and a translator's behaviour cannot be expected to be fully systematic' (Toury [1978] 2004:67). Adequate translation as defined by EvenZohar is '... a translation which realises in the target language the textual relationships of a source text with no breach of its own basic linguistic system' (Even-Zohar [1975] 2004:43). As is the case, it becomes apparent that each and every translation is influenced by elements, such as the target culture, acceptability and the translation strategy (either communicative or semantic) used. Against this backdrop, this research study focuses on the manner and the level in which the afore-mentioned elements influence the translation. Do they influence in such a way that particular shifts occur? Is there any literal translation of certain concepts owing to a lack of equivalence or a move towards a more cultural word that can easily be understood by the target audience? These questions shall be answered in due course in this article (Toury [1978] 2004:88-89).

\section{Acronyms or abbreviations}

Acronyms or abbreviations are commonly used in technical and scientific documents. Not only they constitute the first letters of several words but they also replace longer words with shorter ones. With the advancement of technology, which also brought about longer complicated concepts and terms, there rose the need for abbreviating concepts and simplicity in communication. According to Kasprowicz (2010), abbreviations are a shortened form of a word created from a string of one to several capitalised initial letters or syllables (Kasprowicz 2010 in Kuzmina, Fominykh \& Abrosimova 2015:550). Along the same lines, Borisov (1972) in Kuzmina et al. 2015:551) sees abbreviations as a letter or combination of letters, which have alphabetic similarity with the original word or expression and are used instead of the word or expression for brevity. They are further perceived by Alekseev (1979) as a '... way to create the nominations for the concepts and realities that were originally designated descriptively by attributive phrases, and "abbreves" are the result of this process' (Alekseev 1979:188). Abbreviations are usually used to avoid repetition of sentences and to save up space in a text. They form part of a field jargon, and should only be used in situations where both the writer and reader are familiar with the subject matter. In other words, the writer should always have the target readership in mind before using abbreviations or acronyms. As the pivotal part of this article, the following section discusses the theory of technical translation and terms in detail.

\section{Technical translation and terms}

According to Newmark (1988):

Technical translation is one part of specialized translation; it is primarily distinguished from other forms of translation by terminology, although terminology usually only makes up about $5-10 \%$ of a text. (p. 151)

Byrne (2006:11) sees technical translation as a 'communicative service provided in response to a very definite demand for technical information which is easily accessible (in terms of comprehensibility, clarity and speed of delivery)' Admittedly, any translation that requires specialised terminology in a particular field is technical ${ }^{6}$ (Chesterman 1997), and vocabulary or terminology is the determining feature of a technical document or text (Byrne 2006:3). Technical translation is a specialised domain that requires a specialised approach depending on the specific function of the text. According to Rus and Harpa (2017:841), '[t]he fundamental purpose of scientific discourse is not the mere presentation of information and thought, but rather its actual communication'. In order to put it more simply, technical terms and scientific discourses serve a communicative function in a text. When translating technical documents, the translator has to be well equipped with the knowledge of technical terms and the jargon pertaining to the subject matter (Williams \& Chesterman 2002). However, this theory of technical translation being a mere usage of technical terminology in a text is vehemently opposed by Kastberg (2009) and Stolze (2009) who viewed technical translation as being more than a mastery of technical terms and knowledge of scientific jargon. Technical translation is not a one-for-one exchange of technical terms from one language to another, but an attempt to communicate the same technical meaning in the target language (Hatim \& Mason 1997). It is also more than the management and handling of technical terms but the ability to convey the intended meaning precisely. Thus (Byrne 2006):

[T] he purpose of technical translation is, therefore, to present new technical information to a new audience, not to reproduce the source text, per se, or reflect its style or language. (p. 11)

As already pointed out, technical translation poses many challenges to translators across the world because of the lack of equivalents and terminologies. ${ }^{7}$ As translation involves the transfer and reformulation of the source text message, there is usually a question on whether to take a semantic or communicative approach. According to Ghazzala (1995), semantic translation can be classified into two types: (1) word-for-word translation and (2) direct translation. The first approach focuses on translating individual words without any consideration for the grammatical and other linguistic aspects. It 'involves extreme fidelity to the wording of the source text and forces the translator to set the exact equivalents' (Soualmia 2010:13). This form is firmly supported by Newmark (1988)

6.Specialised terminology makes the text technical.

7.Particularly in cases where the two languages involved differ drastically. 
who believes that translations should have the same effects on their readers, as the source text had on their source readers. He further reiterates that '... translators should translate transgressively, not fluently' (Newmark 1988:112). The latter, direct translation, involves translating directly from the source text whilst considering the grammatical confines and rules of the target language, including linguistic differences. Regardless of the fact that this approach $^{8}$ provides the exact intended meaning on word level, it is strongly opposed by different scholars, such as Ghazzala (1995), Chukovsky (1984) and Lefevere (1975).

According to Chukovsky (1984), 'its adoption frequently leads to a complete distortion of the meaning of the original' (Chukovsky 1984 in Soualmia 2010:14), and it consists of many limitations. On the contrary, the communicative approach allows the translator to translate freely without limitations. In this regard, the translator's objective is to produce a readable text in the target language. ${ }^{9}$ Thus, this form of translation does not follow the text wording of the source text.

In an attempt to provide a solution to this problem of whether to opt for communicative or semantic translation, Toury (1995:13) states that 'translations first and foremost occupies a position in the social and literary systems of the target culture, and this position determines the translation strategies that are employed'. What is referred to in the above statement is the following: the translated text holds a certain position in the literary system of the target language and its culture, and their status is determined by whether the literary system is new, old or peripheral. A further elaboration and demonstration of this are provided in graphs after the second paragraph. It is also through paying attention to the target culture that the translation may receive acceptance by its target readership.

The aim of Toury's case studies is to distinguish trends of translation behaviour to make generalisations regarding the decision-making processes of the translator and then to 'reconstruct' the norms that have been in operation in the translation and make hypotheses that can be tested by future descriptive studies. The definition of norms as provided by Toury (1995) is:

The translation of general values or ideas shared by a community - as to what is right or wrong, adequate or inadequate - into performance instructions appropriate for and applicable to particular situations. Thus, every translation should conform to particular norms that are set in a particular culture or target audience. (in Munday 2008:11)

What this means is, no translation is significant unless there is a consideration of the target culture (Munday 2008). Munday (2008:112) further reiterates that these norms are sociocultural constraints specific to a culture, society and

\section{Semantic.}

9.It is more target text orientated. time. This point is also sustained by the fact that Toury (1995) considers translation to be an activity governed by norms, and these norms 'determine the (type and extent of) equivalence manifested in actual translations' (Toury 1995 in Munday 2008:112). According to Halverson (1997), equivalence is the relationship existing between two entities, and the relationship is described as one of similarity in terms of the number of potential qualities. Similarly, House (1997) considered equivalents as a 'conceptual' basis of translation.

It is also wise to determine the kind of norms used in the translation in question, which is the translation of the JICA from English into Tsonga. Following are the kinds of norms that are dominant during the phenomena of translation as identified by Toury cited in Munday (2008: 112-113):

1. Initial norms - these refer to the general choices made by translators, for example, in the Tsonga target text, as it appears very well under the discussion of results, the translator of the text chose to leave years as they are in the source text, that is, 1950, 1965, 1966, 1990 and so on.

2. Preliminary norms - these refer to factors determining the selection of texts for translation in a specific language, culture or time.

3. Operational norms - these describe the presentation and linguistic matter of the target text.

4. Matricial norms - these relate to the completeness of the target text.

5. Textual linguistic norms - these govern the selection of target text linguistic material: lexical items, phrases and stylistic features.

6. Situating the target text in the target culture system

- The two small boxes within the boxes indicate where the target text can be found within the Tsonga cultural literary system.

- Figure 1 represents the Tsonga literary system.

- Figure 2 represents the English literary system.

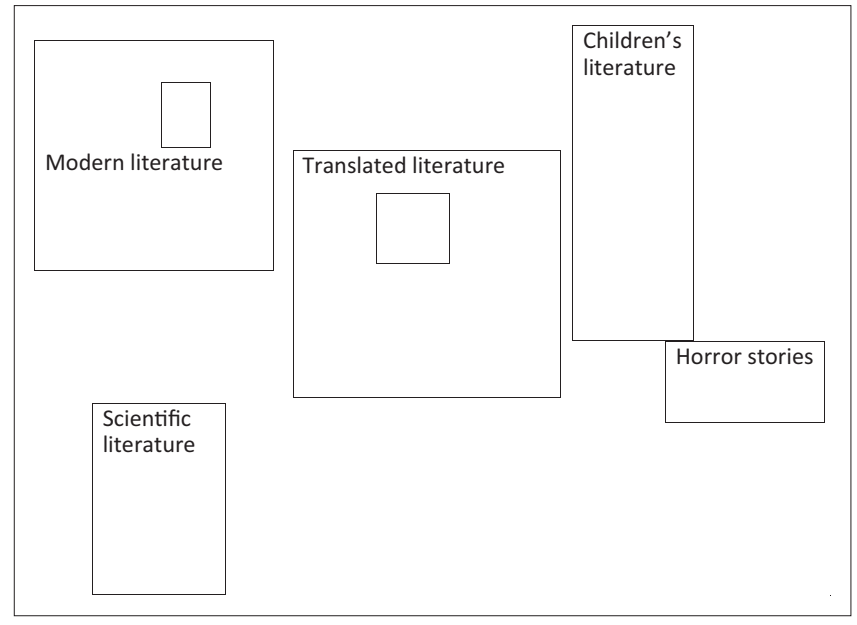

FIGURE 1: A representation of the Tsonga literary system. 


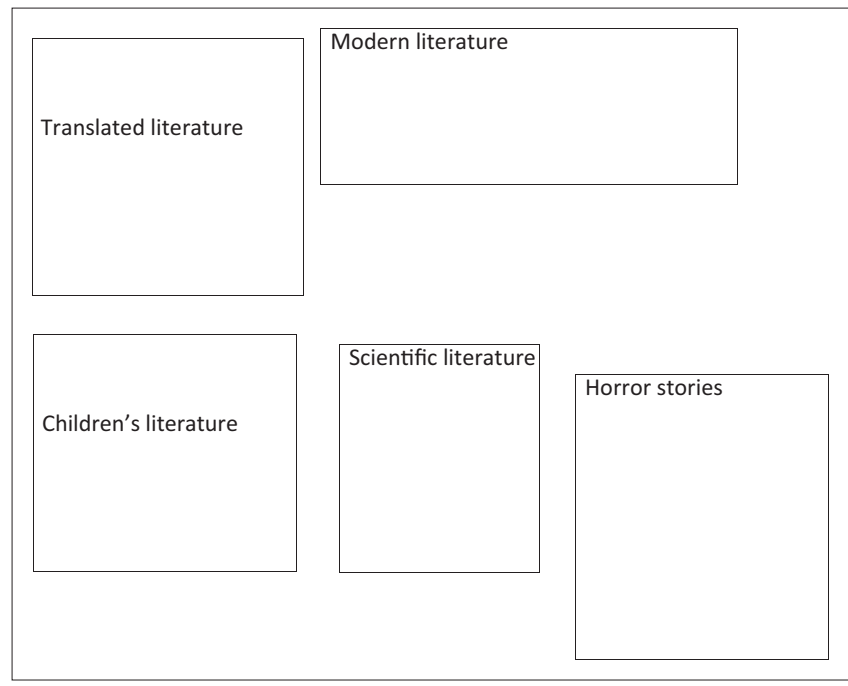

FIGURE 2: A representation of the English literary system.

\section{Differences in the two literary systems (Tsonga and English)}

What transpires from the two figures is that there is a huge difference between the two literary cultures. The English literary culture appears to have all forms of literature, which include modern literature, scientific literature, children's literature and horror stories. Although the Tsonga literary culture also consists of the same, as indicated in the first diagram, the difference is that there is not much link in these literary forms, as indicated by the spaces between the boxes. Contrary to this, the English literary culture links its literary forms; this is indicated by the closeness of the boxes within the second diagram. Thus, because of these links in the English literary culture, it can be represented as having the same readership in any literary form because of the status, development and hegemony of the language. With that being said, the English literary system appears to have small translated literature compared with the Tsonga one, which appears to have almost everything translated into the language because of its minority status and lack of development. Thus, the position of the translation in the target language's literary system will guide the translator to either render a more acceptable or a more adequate form of translation. If the translated literature takes up the dominant position in the literary system of the target language, the target text will follow the source text closely.

The brochure, however, is made available by the JICA which is, as previously indicated, an agency aimed at managing volunteers and persuading people to join the agency in South Africa. Although distributed worldwide, the target readership in South Africa is the youth under the age of 35 years who are willing to be part of the agency. This will fit in both the translated literature and the scientific literature because of its nature. It represents and carries matters that are rarely discussed in the Tsonga literature - technical documents - one very seldom finds the Tsonga technical literature or documents unless translated for a particular purpose. Thus, readership of technical or scientific literature amongst the Tsonga is very limited unless the main objective is to promote or market a particular brand. With that being said, this document occupies a more central and serious part of the Tsonga literary system (Munday 2008:109).

The document, therefore, made available by the JICA will take a primary position in the Tsonga literary culture (Munday 2008) because:

$[W]$ hen there is a critical turning point in literary history at which established models are no longer considered sufficient, or when there is a vacuum in the literature of the country [...] where no type holds sway, it is easier for foreign models to assume primacy. (p. 109)

Correspondingly, almost every Tsonga literature consists of translated materials; from children's literature, scientific literature, to popular literature all are translated from English and the English literary culture is dominant within the Tsonga one, and thus, it assumes primacy within the polysystem.

Additionally, despite the lack of equivalents in the target text, the translator of the afore-mentioned document tries to move a bit closer to the source text and its literary culture system. The culture of the target audience is considered less in instances where equivalents cannot be easily found. For example, the translator sometimes in the document opts to use borrowing often because explaining some of the concepts could even lead to a loss of meaning. Bosco (1997) defines borrowing as the attempt to take words from one language and put them in another language alphabet. These words are naturalised to suit the grammar and the pronunciation of the target language.

Eventually these words become part of the lexicon system of the target language as in Tsonga. Examples include 'Tivholonthiyara' for 'volunteers', 'phirogireme' for 'programme', 'imeyili' for 'email' and 'fekisi' for 'fax'. Thus, moving more towards the target culture would require the translator to provide a long sentence of what volunteers are, thus in turn, even leading to confusion to the reader.

Furthermore, the English version of the JICA moves from the scientific and modern literature to the translated literature in the target culture system. What becomes apparent is the fact that this document adheres to the Tsonga language cultural norms. With that being said, as the main focus of this article was to investigate the treatment of technical words, abbreviations, acronyms and numbers, the reality is that, should there be a lack of equivalents, English technical terms will be naturalised into Tsonga or be kept in their natural form.

\section{Research methodology}

In this research study, Toury's three-phase methodology for systematic DTS is used to describe the translation. Toury (1995:36-39) suggested that the researcher must '... 
incorporate a description of the product and the wider role of the sociocultural system'.

It is through this sociocultural system that this study aims to determine whether the cultural elements of the Tsonga language had an influence on the translation of the text in question. Thus, the treatment of technical terms, acronyms, abbreviations and numbers in the text is investigated, and the outcome of this method was fruitful.

Data analysis in this research study is divided into different sections (according to strategies), and tables are also included where necessary. The analysis of data is largely based on the translation strategies (applied during the translation process $)^{10}$ described by Jeremy Munday (2008:109).

\section{Treatment of technical terms in the Tsonga target text}

It is with no doubt that the lack of development of the Tsonga language leads to the lack of equivalence of English words in Tsonga. The distance in development that exists between these two languages also leads to difficulty during the process of translation. However, translators have come up with solutions that attempt to close the gap between two languages that come from different language families that seek to communicate the same message. In most cases, they have the privilege to decide whether the lexical patterns of the source text can be reformed in the target text or be shifted to form the accepted model of the target language. As the heading states, the researcher seeks to investigate the treatment of technical terms, abbreviations and so on in the Tsonga document.

What transpires from reading the Tsonga translated text is that technical terms are treated differently depending on whether there is an equivalence. Notably, there is a lack of equivalence in almost each and every technical term in the document. However, the employment of derivation, semantic transfer, deideophonisation, paraphrasing, compounding and borrowing in a suitable instance made it possible for the translator to effectively communicate the message of the target text. The following example is a further demonstration and analysis of how technical terms are treated in the Tsonga text:

\section{English}

Since joining the

Colombo plan

\section{Tsonga}

Colombo plan (Kungu leri nga simekiwa hi lembe ra 1950 hi xikongomelo xo ringeta kupfuneta hi tlhelo ra timali ni nhluvukiso wa vanhu ekamatiko lawa ya nga eDzongeniwa Asia)

Most notably, in the Tsonga rendition of 'since joining the Colombo plan', there is a long explanation of what the
Colombo plan is and what it does. This is performed with the main objective of providing the Tsonga literary culture with what the Colombo plan is all about as this (the Colombo plan) is unknown to the Tsonga readership. Thus, the translator opted to use explanation in an attempt to make the translation simpler and aid understanding in the target readership. In order to put it more simply, the explanation provides more clarity to the sentence in question. Other examples of how technical terms are treated are outlined in Table 1.

Furthermore, 'technical assistance' is paraphrased as 'mpfuneto wa swavutivi', which directly translates to 'assistance of knowledge'. As there is no direct equivalence of what 'technical' is in Tsonga, the translator chose to use paraphrasing in order to give a sense of what 'technical assistance' is all about, and as a result, the term takes a more obligatory shift. That is, there is no formal correspondence between the source item and the target item. This is usually performed to find a source item equivalent in the target text (language). According to Bakker, obligatory shifts in translation are the changes that take place during the translation process, and 'it is the outcome that comes from the attempt to deal with the differences between ST and TT languages' (Bakker, Cees \& Van Leuven-Zwart 1998:226).

In light of that, obligatory shifts are probable in cases where the translation process involves two differing languages as it is the case with Tsonga and English.

In some instances, however, some parts of the technical terms are explained or semantically transferred and leaving some other parts as they are. The following example provides a better explanation:

- English: 'official development assistance'

- Tsonga: 'hi rhengu leri ri vuriwaka official development'

Regardless of the fact that 'official development' is kept the same even in the Tsonga text, there is some additional explanation that is aimed at locating and linking the term with the literary Tsonga culture. That is, 'hi rhengu leri ri vuriwaka' is used to support 'official development' as an 'organisation/initiative'

TABLE 1: How technical terms were treated in the Tsonga target text.

\begin{tabular}{|c|c|c|}
\hline English & Tsonga & Back translation \\
\hline $\begin{array}{l}\text { 1. Non- } \\
\text { government } \\
\text { organisation }\end{array}$ & $\begin{array}{l}\text { Ntlawa lowu wu nga riki wa mfumo wu nga } \\
\text { tiyimela hi woxe }\end{array}$ & $\begin{array}{l}\text { A non-government } \\
\text { organisation that } \\
\text { stands on its } \\
\text { own/that is } \\
\text { independent }\end{array}$ \\
\hline $\begin{array}{l}\text { 2. An application } \\
\text { form }\end{array}$ & Fomo ya vuxokoxoko & $\begin{array}{l}\text { Form of } \\
\text { information or } \\
\text { details form }\end{array}$ \\
\hline $\begin{array}{l}\text { 3. Your line } \\
\text { agency }\end{array}$ & Murhangeri wa xiyenge xa wena & $\begin{array}{l}\text { Your section } \\
\text { leader }\end{array}$ \\
\hline $\begin{array}{l}\text { 4. Coordinating } \\
\text { team }\end{array}$ & Ntlawa wa vafambisi & Group of leaders \\
\hline $\begin{array}{l}\text { 5. International } \\
\text { travel }\end{array}$ & Kuendzela entsungeni wamalwandle & $\begin{array}{l}\text { Going to overseas } \\
\text { countries }\end{array}$ \\
\hline $\begin{array}{l}\text { 6. Living } \\
\text { allowance }\end{array}$ & Ntsengo wotihanyisa ha wona & $\begin{array}{l}\text { An amount to live } \\
\text { by }\end{array}$ \\
\hline 7. Equipment cost & Ntsengo wa switirhisiwa & Cost of equipment \\
\hline
\end{tabular}


(domestication). ${ }^{11}$ The Tsonga equivalence directly translates to an 'organisation called official development'. Albeit there is a direct equivalent for 'official development' the critique is that the original translator chose to leave the original source phrase as it is. This foreignisation ${ }^{12}$ strategy may cause challenges for readers who do not have an understanding of the English language. Notably, the translator cunningly applied both the domestication and the foreignisation strategies in the same sentence. These strategies have been proven to be effective, and are supported by Munday (2001), Shuttleworth and Cowie (1997) and Yang (2010). Obeidat and Mahadi (2019) refer to the works of Venuti (1995) and Munday (2001) by emphasising that both domestication and foreignisation are the basis of translation in cases where different cultures and culture-specific sources are involved (Obeidat \& Mahadi 2019:158). As Munday (2001) puts it:

[D]omestication and foreignisation come out to answer the question of how to bridge the gulf that had grown between the writer or the source text which is written in a language that is very culture-bound and the target-text writer. (p. 42)

From Munday's assertion, it can be concluded that the act of translating expands beyond linguistic boundaries to cultural ones. However, regardless of this criticism, needless to say, translators make choices and decisions during the translation process. The choices that they make and their 'translation style ${ }^{\prime 13}$ determine the outcome of the target text. Also, in cases where equivalent issues may arise, loan words, or loan translations and even semantic shifts may be employed (Jacobson 1959:234). In support of the translator's freedom of choice, Popovic (1970) asserts that:

The translator's business is not only to 'identify himself/herself with the original', the translator also has the right to differ naturally, to be free, as long as this freedom is for the sake of the original to be reproduced as a living work. Thus shifts do not happen because the translator desires to 'change' a work, but because he/she strives to reproduce it as devotedly as a possible. (p. 80)

Through reading both the English source text and the Tsonga target text, it becomes apparent that technical terms in the Tsonga text are treated differently depending on what the term entails but are predominantly translated by paraphrasing and borrowing as has been indicated in the above examples. Many phrases have been paraphrased, it is again, because of the lack of direct equivalents. Some more examples of paraphrasing in the text include the following (Table 2).

11.According to Munday (2001), domestication strategy is when elements of the source text, foreign elements are minimised into the target language values (Munday 2001:76). The strategy avoids imposing the source language culture to the target reader.

12.Foreignisation may be defined as keeping the foreign values of the source text in the target text (target language). This strategy exposes the source language culture to the target language culture.

13.This defined by Ghazzala (2006:222) as 'the different choices made in texts from language reservoir in regard to grammar, words and phonology, namely all aspects, levels and components of language'.
TABLE 2: Examples of paraphrased words in the text.

\begin{tabular}{|c|c|c|}
\hline $\begin{array}{l}\text { Technical term in } \\
\text { English ST }\end{array}$ & $\begin{array}{l}\text { How the technical term has } \\
\text { been translated into Tsonga }\end{array}$ & Back translation \\
\hline 1. Technical cooperation & Mpfuneto wa swavutivi & Assistance on knowledge \\
\hline 2. Dispatch of experts & Lava va nga na vutivi & Those who have knowledge \\
\hline 3. Concessionary loans & $\begin{array}{l}\text { Kulombisiwa ka mintsengo } \\
\text { yalehansi }\end{array}$ & Lending of small amounts \\
\hline 4. First aid & $\begin{array}{l}\text { Vanyiketa mpfuno wo } \\
\text { sungula }\end{array}$ & $\begin{array}{l}\text { Those who provide first } \\
\text { assistance }\end{array}$ \\
\hline 5. Volunteers & Tivholonthiyara & Volunteers \\
\hline 6. Types of volunteers & Tinxaka ta tivholonthiyara & Types of volunteers \\
\hline 7. Senior volunteer & $\begin{array}{l}\text { Mupfuneti loyi a nga eka } \\
\text { xiyimo xalehenhla }\end{array}$ & $\begin{array}{l}\text { An assistant who is of a } \\
\text { higher status }\end{array}$ \\
\hline
\end{tabular}

TABLE 3: How abbreviations and acronyms were handled in the Tsonga target text.

English definition Tsonga equivalence Back translation where
applicable

JICA (Japan International Nhlangano wa vuyimeri A representative organisation Cooperation Agency) emisaveni hinkwayo lowu in the whole world that

wu humaka eJapani comes from Japan

ODA (Official Rhengu leri ri vuriwaka An initiative that is called

development assistance) 'official development 'official development assistance' assistance

JOCV (Japan Oversees Mintirhisano ya vapfuneti Japanese cooperation of \begin{tabular}{ll} 
Cooperation Volunteers) & $\begin{array}{l}\text { yale Japani entsungeni wa assistants overseas } \\
\text { malwandle }\end{array}$ \\
\hline
\end{tabular}

In conclusion, the translator applied the paraphrasing and domestication strategy to try and avoid imposing the source language culture to the Tsonga audience. The examples of technical terms in the table were handled with a communicative strategy (paraphrasing and domestication), which allows the reader to have a better understanding of the text in question, as the translation incorporates both their language and culture. Therefore, this strategy allowed for 'dynamic equivalents'.

\section{Treatment of abbreviations or acronyms in the Tsonga target text}

What stands out the most in this text is that the treatment of abbreviations is not the same. ${ }^{14}$ In the first page of the document in question, there is not even a single description or explanation of what the abbreviations stand for. Notably, in the first page of the document, the abbreviations 'JICA' and 'ODA' are used multiple times without any explanation of what they stand for. But surprisingly, definitions of these abbreviations are provided in the source text; in fact, the explanation is provided first, with the abbreviation in brackets on the side.

As one goes through the pages, however, it is found that description of these abbreviations is offered in English (but not in the Tsonga text), and the translation of the description is made particularly with the new ones being introduced: JOCV (Japan Oversees Cooperation Volunteers) and SV (Senior Volunteers).

By having a closer analysis of the handling of acronyms and abbreviations in Table 3, it can be suggested that acronyms and abbreviations should always be accompanied by explanations of what they stand for. This suggestion is strengthened by the fact that abbreviations and acronyms may stand for different things in different contexts, 14.Acronyms are used without explanation in the first page of the document. 
particularly in languages that lack scientific terminology of their own, as is the case with Tsonga.

Furthermore, if used independently, acronyms or abbreviations may not be able to form part of the target language and literary culture.

\section{Treatment of numbers in the Tsonga target text}

When it comes to the treatment of numbers in the text, the Tsonga direct equivalent is given in letters and the numeric is placed in brackets (Table 4). This is performed because the translator tries to move towards the Tsonga literary culture, which promotes and allows the use of numbers in its literature. Nonetheless, the shift made here is non-obligatory as anyone who can read and write Tsonga is able to understand the numeric form.

Contrary to that, with years, they are only kept numerically without any Tsonga explanation in letters, for example, 1950, 1954, 1965, 1966, 1990 and 2011 throughout the text they are kept the same. Thus, numbers are treated differently in the Tsonga target text depending on what they represent. In substantiating this, one can refer to Vinay and Darbelnet's model (1995). They have seven standards that can be applied in translation; but for the purposes of this research, only the relevant ones are going to be referred to:

1. Equivalence $^{15}$ - this refers to cases where languages describe the same situation by different stylistic or structural means.

2. Adaptation ${ }^{16}$ - this involves changing the cultural reference when a situation in the source culture does not exist in the target culture.

These two of the seven standards explain the treatment of years in the target text. The style that the translator employed with regard to years is different from the one used with numbers, as they both explain the same thing in the same manner. Thus, in this regard, the translator's choices were non-obligatory.

\section{Conclusion}

Although translation is a transfer of the message from the source language to the target language, there are different challenges that translators have to face when translating technical documents (texts). Not withstanding, this study has revealed the different translation strategies applied in the treatment of technical terms, abbreviations or acronyms and numbers in a Tsonga technical target text. In cases where there would be a lack of technical term equivalents,

15.This technique requires the translator to be creative, especially in the case of translating idioms, proverbs or slogans of advertising. This process allows the translator to reduce or expand the number of words, but not to drop crucial information.

16.In this type, the translator attempts to make textual materials that are specific to a given language culturally appropriate to another language (Soualmia 2010).
TABLE 4: How numbers were treated in the Tsonga target text.

\begin{tabular}{ll}
$\begin{array}{l}\text { Treatment of numbers in } \\
\text { the English source text }\end{array}$ & Treatment of numbers in the Tsonga target text \\
\hline 1.150 & Dzana na makume ntlhanu (150) \\
\hline 2.100 & Dzana (100) \\
\hline 3.20 & Makume mbirhi (20) \\
4.39 & Makume nharhu-nkaye \\
5.8 & Nhungu (8) \\
6.120 & Dzana na makume mbirhi (120) \\
7.1046 & Gidi na makume mune-ntsevu (1046) \\
\hline
\end{tabular}

the translator would either naturalise the term, explain it or leave it in its original form in cases where the original form can be understood by the reader without any struggle. In some instances, neologism, which is the introduction of new concepts and terms by translating the meaning, was used whenever there was a need, without jeopardising the Tsonga grammatical structures. Not only did this strategy work in providing equivalents in the target text but it also created terms that can be used in future Tsonga technical translations. Albeit different functional strategies have been deployed in the translation of the JICA document, one of the greatest shortcomings revealed by the analysis of results (technical terms in particular) is the lack of consistency in the translation and the application of these strategies. As revealed by the back translations provided, some of the translations would not make sense to readership without background knowledge of the subject matter. Thus, translation of technical terms from English into Tsonga involves more than a transfer of meaning; there are different aspects, such as the target readership culture, situating the text into the target culture literary system that have to be considered at all times. Because of the lack of scientific equivalents in African indigenous languages, translators are advised to employ the domestication strategy, which is useful when translating technical terms and concepts from English into Tsonga whilst remaining faithful to the target language. Therefore, a successful translator of technical documents is the one who considers every translation task as a unique case that requires investigation. They apply relevant translation strategies that effectively aid in the transfer of message from the source text to the target text whilst considering its literary culture.

\section{Acknowledgements Competing interests}

The author declares that they have no financial or personal relationships that may have inappropriately influenced them in writing this article.

\section{Author's contribution}

L.C. is the sole author of this research article.

\section{Ethical considerations}

This article followed all ethical standards for research without direct contact with human or animal subjects. 


\section{Funding information}

This research received no specific grant from any funding agency in the public, commercial or not-for-profit sectors.

\section{Data availability}

Data sharing is not applicable to this article as no new data were created or analysed in this study.

\section{Disclaimer}

The views and opinions expressed in this article are those of the author and do not necessarily reflect the official policy or position of any affiliated agency of the author.

\section{References}

Alekseev, D., 1979, Sokrashchennye slova $v$ russkom yazyke [Abbreviated words in Russian], Saratov University, Saratov.

Bakker, M., Cees, K. \& Van Leuven-Zwart, K., 1998, 'Shifts of translation', in M. Baker (ed.), Routledge encyclopedia of translation studies, pp. 226-231, Routledge, London.

Bosco, G., 1997, Translation techniques, viewed 20 May 2010, from https://www. interproinc.com/blog/translation-techniques.

Byrne, J., 2006, Technical translation: Usability strategies for translating technical documents, Springer, Dordrecht.

Chesterman, A., 1997, Memes of translation: The spread of ideas in translation theory, Benjamins, Amsterdam.

Chukovsky, K., 1984, The art of translation: Kornie Chukovsky's "A High Art" (edited \& translated by Laurent G. Leighton), University of Tennessee Press, Knoxville, TN.

Even-Zohar, I., [1975] 2004, 'The position of translated literature within the literary polysystem', in L. Venuti (ed.), In spite of the broad recognition among historian of: The Translation Studies Reader, p. 199, Duke University Press, Durham, NC.

Ghazzala, H., 1995, Translation as problems and solutions: A course-book for university students and trainee translators, Elga Publication, Valetta Malta.

Halverson, S., 1997, 'The concept of equivalence in translation studies: Much ado about something', Target. International Journal of Translation Studies 9(2), 207-233.

Hatim, B. \& Mason, I., 1997, The translator as communicator, Routledge, London.

Hosseinimanesh, L. \& Dastjerdi, H., 2013, 'Technical translation: A study of interference in three Persian translations of "Software Engineering", Journal of Language Teaching and Research 4(1), 156-163.

House, J., 1997, Translation quality assessment: A model revisited, Gunter Narr Verlag, Tübingen.

Jacobson, R., 1959, 'On linguistic aspects of translation', On translation 3(2), 30-39.
Kasprowicz, M., 2010, Handling abbreviations and acronyms in medical translation, viewed 15 August 2020, from https://translationjournal.net/journal/52abbreviations. $\mathrm{htm}$.

Kastberg, P., 2009, 'Cultural issues facing the technical translator', The Journal of Specialised Translation 11(8), 104-109, viewed 29 October 2020, from https:// www.jostrans.org/issue08/art_kastberg.pdf.

Kuzmina, O., Fominykh, A. \& Abrosimova, N., 2015, 'Problems of the English abbreviations in medical translation. GlobELT: An International Conference on Teaching and Learning English as an Additional Language, Antalya - Turkey', Procedia - Social and Behavioural Sciences 199(2015), 548-554. https://doi. org/10.1016/j.sbspro.2015.07.545

Lefevere, A., 1975, Translating poetry: Seven strategies and a blueprint, Van Goreum, Assen.

Maluleke, M., 2017, 'The role of Bible translation in enhancing Xitsonga cultural identity', PhD thesis, University of Free State.

Munday, J., 2001, Introducing translation studies, theories and applications, Routledge, London.

Munday, J., 2008, Introducing translation studies: Theories and applications, 2nd edn., Routledge, London.

Newmark, P., 1981, Approaches to translation, vol. 1, Pergamon Press, Oxford.

Newmark, P., 1988, A textbook of translation, Prentice Hall, Singapore.

Newmark, P., 1991, About translation, Multilingual Matters, Clevedon.

Obeidat, A. \& Mahadi, T., 2019, 'The translation of Arabic religious-cultural collocations in literary texts into English: An application of domestication and foreignization translation strategies', International Journal of Humanities, Philosophy and Language 2(6), 155-165. https://doi.org/10.35631/ijhpl.260013

Popovic, A., 1970, 'The concept shift of expression in translation', in J. Holmes (ed.), The nature of translation, pp. 78-87, The Hague, Mouton.

Rus, D. \& Harpa, E., 2017, 'Technical vs. general translation practices and methods: A comparative study', 11th International Conference Interdisciplinarity in Engineering, INTER-ENG 2017, Tirgu-Mures, 5th-6th October 2017.

Shuttleworth, M. \& Cowie, M., 1997, Dictionary of translation studies, St. Jerome Publishing, Manchester, 192, p.193.

Soualmia, M., 2010, 'Third year students' difficulties in translating computing terms from English into Arabic', Master's dissertation, Mentouri University-Constantine.

Statistics South Africa, 2011, Statistical release-P0301, Statistics South Africa, Pretoria.

Stolze, R., 2009, 'Dealing with cultural elements in technical texts for translation', The Journal of Specialised Translation (11), 124-142.

Toury, G., [1978] 2004, 'The nature and role of norms in literary translation', in $\mathrm{L}$. Venuti (ed.), The translation studies reader, pp. 205-218, Routledge, New York, NY.

Toury, G., 1980, In search of a theory of translation, Porter Institute, Tel Aviv.

Toury, G., 1995, Descriptive translation studies and beyond, John Benjamins, Amsterdam. Venuti, L., 1995, The translator's invisibility: A history of translation, Routledge, London.

Vinay \& Darbelnet, J., 1995, Comparative stylistics of French and English: A methodology of translation, vol. 11, John Benjamins, Amsterdam.

Williams, J. \& Chesterman, A., 2002, The MAP: A beginner's guide to doing research in translation studies, St. Jerome, Manchester.

Yang, W., 2010, 'Brief study on domestication and foreignization in translation' Journal of Language Teaching and Research 1(1), 77-80. https://doi.org/10.4304/ jltr.1.1.77-80 